\title{
A COMPARISON OF THE SISI AND THE STAPEDIUS REFLEX TEST IN THE DIFFERENTIAL DIAGNOSIS OF COCHLEAR PATHOLOGY
}

\author{
LINDA BLOCK, B.A. (Sp. \& H. Therapy) (WITWATERSRAND) \\ Forest Town School for Cerebral Palsied Children, Johannesburg.
}

\begin{abstract}
SUMMARY
Previous research has cast doubt on the reliability and validity of "the SISI in the differential diagnosis of cochlear pathology. This study further evaluates this test by comparing it to the Stapedius Reflex Test, a test of recruitment and cochlear pathology. Two groups of 10 subjects each were selected (36 cars). The first had cochlear pathology as detected by the reflex test, and the second, the control group, had normal cars. The results revealed that the SISI was significantly inferior to the reflex test in the detection of cochlear pathology. Possible modifications of the SISI are suggested.
\end{abstract}

\section{OPSOMMING}

Vroeëre navorsing betwyfel die betroubaarheid en geldigheid van die SISl-toets in die differensiële diagnose vir cochlieêre patologie. Hierdie studie cvaluecr verder die S1Sl-toets deur dit met die SRT, 'n tocts vir herstel en cochlieêre patologie, te vergelyk. Twee groepe van tien pasiënte elk is ondersoek, die eerste groep me t cochlieêre patologie soos deur die reflekstoe ts uitgewys en 'n kon trole groep met normale gehoor. Die resultate toon aan dat die SISI-toets minder waardig is teenoor die reflekstoets, vir die diagnosering van cochlieêre patologic. Moontlike wysigings aan die SISI-toets word voorgestel.

The Short Increment Sensitivity Index (SISI) is a test commonly used in the differential diagnosis of cochlear pathology. It measures the ability to detect remarkably small changes in sound intensity, assumed to be related to the presence of a suprathreshold phenomenon known as loudness recruitment. ${ }^{12}$ Recruitment is defined by Hirsh et al. ${ }^{11}$ as ' . . . a more-rapid-than-normal increase in subjective loudness for a given increase in physical intensity'. The presence of recruitment has been proved to be indicative of cochlear pathology., 31 The tests measuring the phenomenon therefore play an important role in the diagnosis of site of lesion in sensori-neural hearing impairment.

The SISI has been regarded as an indirect test of recruitment, because of the assumption that the ability it measures is due to the presence of recruitment. The basic rationale for this assumption is that . ... if the loudness is increasing more rapidly than normal as the stimulus intensity is increased, a smaller than normal amount of intensity change is necessary for a jnd (just noticeable difference) in loudness.' ${ }^{10}$ This rationale was later found to be invalid, on the basis that a linear relationship between loudness and intensity does not exist. ${ }^{11}$ Consequently, workers in the field appear to have abandoned SISI as an indirect test of recruitment.

Jerger $^{13}$, however, believed that the test did have some value. This belief was 
based on the observation that certain patients (generally those with recruitment) are often able to detect smaller changes in intensity at comparable levels above threshold, ${ }^{13}$ and these patients were found to have cochlear pathology. Whether these patients had recruitment or not, was not felt to be of importance. Jerger believed that the primary issue in determining the value of this test was whether it was a true test of site of lesion, and not whether it correlated with direct tests of recruitment.

It is felt by some writers, however, that since recruitment is generally accepted as evidence of cochlear pathology, there should be a close relationship between a high SISI score and the presence of recruitment. ${ }^{24,31}$ The validity of the SISI has been queried in the literature. High SISI scores have been found in patients with acoustic neuromas, ${ }^{13}, 23,31$ as well as in subjects with normal ears. ${ }^{14,23,26,27,32}$ Some investigators have shown the SISI score to be related to the sound pressure level (SPL) of the tone. ${ }^{32}$ Given the same SPL as pathological ears, normal ears also achieve high SISI scores.

The reliability of the SISI is also questionable since the test relies on the subjective decision of the individual and has been found to be susceptible to factors such as boredom and fatigue. ${ }^{7}$ Thus doubt has been cast on both the validity and reliability of the SISI as a differential diagnostic test of cochlear pathology.

The Stapedius Reflex Test (reflex test) involves the objective measurement of the recruitment phenomenon, and as such is regarded as a site-of-lesion test. The test is one of three tests of an impedance audiometric battery. Basically, it involves the measurement, by an impedance audiometer, of the alteration in the impedance of the middle-ear system caused by the reflex contraction of the stapedius muscle: ${ }^{20}$ The reflex is elicited bilaterally and consensually via the cochlea and brain stem in response to an acoustic stimulus. ${ }^{28}$ It is believed to be related to the subjective loudness experience of the stimulus rather than the absolute intensity. ${ }^{5,14,20,28}$ As such, the reflex threshold, measured as the lowest sound intensity capable of eliciting a detectable contraction of the stapedial muscle, ${ }^{16}$ yields objective evidence of the loudness growth pattern of the ear. ${ }^{19}$ In a patient with an abnormally rapid growth of loudness (re-cruitment), it has been found that the reflex will be elicited at the same sound intensity as in normal ears (i.e. $70-90 \mathrm{~dB}$ ), but producing an abnormally small sensation level (SL) due to the elevated pure-tone thresholds. $^{4}, 5,15,16,20,21$

Lidén in $1970^{18}$ concluded from his experimental and clinical studies, that '. . . loudness recruitment established by means of the stapedial reflex test is equivalent to the presence of a lesion in the cochlea'. His findings confirmed those of Metz. ${ }^{21}$

The reflex test has the advantages of not being restricted in applicability; of being objective; and of being quick and simple to administer. ${ }^{15}$ It does not require any voluntary response from the subject and is thus more reliable than the SISI. Its only major disadvantage is that a number of factors, other than the absence of recruitment, can prevent the reflex from being elicited. If no recruitment is present, the limits of the audiometer (usually $110 \mathrm{~dB}$, ISO 1964) will not allow for the production of a stimulus of sufficient intensity 
to elicit the reflex. ${ }^{6,16}$ However, pathological conditions of the middle-ear or tympanic membrane, as well as a reflex arc which is not intact (as in Bell's Palsy, for example), will also prevent the reflex's elicitation. ${ }^{15,}{ }^{30}$ Furthermore, the reflex has been found to be absent in a certain percentage of normal ears. ${ }^{3}, 15,28$ These findings led Thompsen ${ }^{30}$ to state that: "While thus a positive result (demonstrative of recruitment) is altogether conclusive evidence, the same significance cannot quite be attached to a negative result'.

The reflex test has therefore been widely accepted as a valid and reliable test of the recruitment phenomenon and as such, as a test of cochlear pathology. This study was designed to re-evaluate the reliability and validity of the SISI by comparing it to the reflex test in its ability to differentially diagnose cochlear pathology.

\section{METHOD}

\section{SUBJECTS}

Two groups of subjects (Ss) were selected; one group with cochlear pathology (designated Group P), and the other with normal ears (designated Group N).

Group P: This comprised ten Ss with bilateral mild to moderate sensori-neural hearing loss, selected from the files of the Speech and Hearing Clinic at the University of the Witwatersrand, Johannesburg.

The thresholds of these Ss were from 20 to $65 \mathrm{~dB}$ at a minimum of two of the frequencies $500,1000,2000$ and $4000 \mathrm{~Hz}$. The mean auditory threshold was $34 \mathrm{~dB}$. Four Ss were female and six male, ranging in age from $20-50$ years with a mean age of 35.5 years. Ss with hearing loss of less than $65 \mathrm{~dB}^{3}$ were selected to prevent, as far as possible, the elicitation of the reflex being precluded by the limits of the audiometer. For the purpose of this study, the etiology of the hearing loss was not ascertained.

Group N: Ten Ss with bilaterally normal auditory thresholds were randomly selected from the Residence population of the University of the Witwatersrand, as a control.

The criterion of normality was bilateral auditory threshold sensitivity of $15 \mathrm{~dB}$ or less over the entire frequency spectrum. No Ss had any previous history of ear problems, and recordable stapedius reflexes were required in at least one ear. Six Ss were female and four male, ranging in age from 20-24 years with a mean age of 22 years. All Ss, in both groups, were untrained listeners with little or no knowledge of the audiological test procedures. No S had any prior knowledge of the study.

\section{EQUIPMENT}

All tests were administered in an acoustically treated booth (IAC series 1604 Act.). The Maico Model MA-24 Dual Channel Research and Diagnostic Audiometer was used for the administration of pure-tone audiometry and the SISI. For the reflex test, the Madsen ZO-70 Electro-Acoustic Impedance Bridge, with a type TDH 39 earphone attached to the headset, was connected to an Amplivox 103 Audiometer (maximum intensity output $110 \mathrm{~dB}$ ). All machines had been recently calibrated according to the ISO (1964) reference zero level. 


\section{TESTS ADMINISTERED}

Three tests were administered in the study: Pure-tone audiometry; followed by the two tests to be compared, the SISI and the Stapedius Reflex Test.

Pure-tone Audiometry: Conventional pure-tone audiometry was administered to order to establish present auditory thresholds. Pure-tone thresholds were established first, as these formed a basis for the selection of Ss. Also, the hearing levels (HL's) at which further tests were to be administered were determined with reference to these thresholds.

In Group $\mathrm{P}$, bone-conduction in addition to air-conduction thresholds were established, in order to ascertain the absence of any conductive component in the hearing impairment. In Group $\mathrm{N}$, bone-conduction thresholds were assumed normal if hearing was normal as tested by air-conduction. ${ }^{22}$

Pure-tone thresholds were established using the "method of limits".22 A descending method of threshold determination was employed. Hood's shadow or masking technique was employed in the determination of bone conduction thresholds. ${ }^{22}$ Threshold curves were charted on a conventional audiogram.

The SISI: As recommended by Harford, ${ }^{9}$ the SISI was administered immediately after the establishment of pure-tone thresholds. Furthermore, early administration of this test minimised, as far as possible, subjective factors such as loss of attention and boredom to which the SISI is believed to be susceptible. ${ }^{7}$

After giving the $S$ the necessary instructions, ${ }^{9}$ the test was administered according to the conventional procedure as described by Jerger. ${ }^{17}$ He utilised a $1 \mathrm{~dB}$ increment superimposed on a continuous tone presented at $20 \mathrm{~dB} \mathrm{SL}$, at each frequency. The test run, consisting of twenty $1 \mathrm{~dB}$ increments, was commenced after the presentation of five $5 \mathrm{~dB}$ practice increments. After every five increments a "check" increment of either $0 \mathrm{~dB}$ or $5 \mathrm{~dB}$, depending on the S's responses was inserted. The SISI score was calculated by determining the number of $1 \mathrm{~dB}$ increments out of twenty responded to, and multiplying the total by five to yield a percentage at each frequency.

The Stapedius Reflex Test: This test was administered last as it does not require any voluntary response from the $S$ and is therefore not susceptible to the aforementioned subjective factors.

Stapedius reflex thresholds were determined according to the procedure outlined in the Madsen ZO-70 handbook. ${ }^{20}$ The reflex threshold was taken as the lowest level capable of eliciting an observable deflection of the balance meter needle. ${ }^{15}$ The sensation level of the reflex threshold was then calculated relative to the pure tone threshold.

\section{FREQUENCY SELECTION}

The most central frequencies were selected for this study. Additional frequencies were not utilized as it was felt that this would tire the Ss, and make the SISI therefore more susceptible to subjective factors. Frequencies were tested in the order $1000,2000,4000$ and $500 \mathrm{~Hz}$. 


\section{CLASSIFICATION OF SCORES}

Scores obtained on the SISI and the reflex test were classified as shown in Table I. The SISI is traditionally classified in to three categories, positive, questionable and negative. ${ }^{24}$ The reflex test is classified only into positive and negative. ${ }^{20}$ A positive score on both tests indicates the presence of cochlear pathology, and a negative score the absence of cochlear pathology.

\begin{tabular}{|l|c|c|c|}
\hline \multirow{2}{*}{ CATEGORIES } & \multicolumn{2}{|c|}{ SISI SCORE } & \multirow{2}{*}{$\begin{array}{c}\text { REFLEX } \\
\text { THRESHOLD }\end{array}$} \\
\cline { 3 - 4 } & Jerger & $\begin{array}{c}\text { Modified } \\
\text { Jerger }\end{array}$ & \\
$\begin{array}{l}\text { Positive } \\
\text { (Cochlear pathology) }\end{array}$ & $60-100 \%$ & $60-100 \%$ & $60 \mathrm{~dB}$ SL and below \\
$\begin{array}{l}\text { Questionable } \\
\begin{array}{l}\text { Negative } \\
\text { (no cochlear pathology) }\end{array}\end{array}$ & $0-20 \%$ & $0-19 \%$ & Above 60 dB SL \\
\hline
\end{tabular}

TABLE I: Method of Test Score Classification

In classifying the SISI scores, the categories of Jerger ${ }^{14}$ were modified slightly so as not to overlap, thereby facilitating statistical analysis. Both the original and modified categories are represented in Table $\mathbf{I}$.

The criterion of $60 \mathrm{~dB}$ as a critical level of recruitment was used in the reflex test (See Table I). This was found by the majority of investigators to be the most valid criterion. $5,15,20$

\section{STATISTICAL METHODS}

Results for Group P and Group N were computed separately. Of the total of twenty Ss (i.e. forty ears), two in each group had no recordable reflex in one ear. These ears were excluded from the computation, leaving thirty-six remaining ears, eighteen in each group. The re were four scores per ear on each test, one at each of the four frequencies tested, making the total number of scores seventy-two per test. The difference between the number of positive scores obtained on the two tests in each group was then calculated and the significance of this difference determined.

\section{RESULTS}

The results of Group P are depicted in Table II. 


\begin{tabular}{|c|c|c|c|c|c|}
\hline GROUP P & & & & & \\
\hline Test & $500 \mathrm{~Hz}(18)$ & $1000 \mathrm{~Hz}(18)$ & $2000 \mathrm{~Hz}(18)$ & $4000 \mathrm{~Hz}(18)$ & Total (72) \\
\hline Reflex & 8 & 12 & 15 & 14 & 49 \\
\hline SISI & 0 & 1 & 5 & 5 & 11 \\
\hline \multicolumn{6}{|l|}{ GROUP N } \\
\hline Reflex & 0 & 0 & 0 & 0 & 0 \\
\hline SISI & 0 & 1 & 0 & 1 & 2 \\
\hline
\end{tabular}

TABLE II: Number of Positive Scores in Group P and Group N (Figures in brackets reflect total number of scores)

Forty-nine of the 72 scores were positive on the reflex test; 11 of the 72 scores were positive on the SISI. There were thus 38 more positive scores on the reflex test than on the SISI.

This is a large difference, and the probability of it occurring by chance alone is is extremely small: $Z-7,6 \quad p<0.001$

Hence this difference is highly significant. The same applies to the results found at the individual frequencies, where the difference between the findings on the two tests was also significant.

In Group N (Table II) none of the 72 scores were positive on the reflex test. On the SISI two were positive.

\section{DISCUSSION}

Jerger ${ }^{13}$ believed that the primary issue in evaluating the SISI was whether it was a true test of site-of-lesion (cochlear or retrocochlear). The reflex test in the present study indicated the presence of cochlear pathology in Group P. This pathology, however, was not detected by the SISI on a significant number of occasions. The scores thus indicated a normal condition when in fact cochlear pathology was present. The SISI is therefore not an adequate site-oflesion test on the basis of the present findings.

As expected, no cochlear pathology was detected by the reflex test in Group $\mathrm{N}$, thus confirming the reliability of this test. In the case of the SISI, however, the two positive scores in this group, although a very small proportion of the total number of scores, do cast doubt on the reliability of this test. This is especially true in view of the fact that positive scores in normals on the SISI have been reported. ${ }^{14,23}$

The number of scores falling in to the "questionable" category on the SISI should also be considered. In Group P, 14 of the 72 scores were "questionable". If these scores are taken as being positive, the difference between the 
number of positive scores on the two tests is still significant. In Group N, however, 23 of the 72 scores were "questionable". If these are included as positive scores, even further doubt is cast on the validity.and reliability of the SISI, since there would then be a greater number of false positives.

It was noted that 49 of the 72 scores in Group P were positive. The remaining 23 negative scores can be accounted for by the following:

1) The presence of a normal threshold at the frequency at which the negative score was obtained.

2) The presence of a retrocochlear lesion. Although recruitment was present at at least two frequencies in each ear, indicating the presence of cochlear pathology, it has been reported that dual loci of lesions can exist. ${ }^{14,31}$

The amount of recruitment present has been found to increase with increasing hearing loss. ${ }^{25}$ This was borne out in the present study by the finding that decreasing size of reflex SL corresponded with ascending size of auditory threshold. The measurement of the reflex SL consequently has additional value in that it yields quantitative as well as qualitative evidence of recruitment. This trend was not evident in the SISI results where no systematic relationship was found between the SISI score and the degree of loss. This also implies, contrary to the findings of some previous investigators, ${ }^{32}$ but in support of Yantis and Decker, ${ }^{31}$ that the SISI score is not a function of the SPL of the tone.

As mentioned earlier, it is generally accepted that the stapedius reflex is elicited at a sound intensity of 70-90 dB in both normal and recruiting ears. By combining the reflex SL's with the threshold values, the HL's of the reflexes are obtained. Sixty-six of the 72 scores in Group P, and 68 of the 72 scores in Group $\mathrm{N}$ fell within these limits. As mentioned initially, the reflexes could not be recorded in two ears in each group. The possible reasons for this are manifold, and cannot necessarily be attributed to the absence of recruitment. ${ }^{30}$ This illustrates the notion discussed earlier that a limitation of the reflex test as a test of recruitment is that a negative result cannot be taken as demonstrative of the absence of recruitment.

Generally agreement was found between the present results in the reflex test and those reported in the literature. This seems to emphasize that results obtained on this test are consistent, and highlights the reliability and validity of the test. The SISI, on the other hand, was found to be unreliable and/or invalid. It was felt that the test could perhaps be improved by the introduction of various modifications to the standard form of the test. These modifications are considered below.

\section{SUGGESTED MODIFICATIONS OF THE SISI}

The size of the practice increments. The conventional procedure of changing from the $5 \mathrm{~dB}$ increments used for practice to the $1 \mathrm{~dB}$ increments of the test itself may be too abrupt. ${ }^{23,31}$ Many Ss may find it difficult to make the subjective decision that the initial test increments are the ones to which they should respond. ${ }^{23}$ This could cause Ss to miss the first few increments, resulting in generally lower SISI scores, and this appeared to occur in the present 
study. Harford ${ }^{9}$ suggested that the practice run should consist of gradually reduced increments from 4 or $5 \mathrm{~dB}$ to $2 \mathrm{~dB}$. In the present study it was also observed that $S$ s often missed the first few increments after the inserted $5 \mathrm{~dB}$ "check" increments. It is therefore suggested that in addition to Harford's modification, the "check" increments be reduced in intensity to a level dependent on the smallest increment the patient is able to hear, as determined during the practice run.

The instructions. The recommended instructions are to respond only when the $S$ is sure that the increment was heard. This has been reported to result in a general tendency of reduction in positive SISI scores. ${ }^{26}$ It is suggested, therefore, that instructions should not include the phrase "if you think you heard the jump, but you're not sure, don't do anything", 9 unless the patient is thought to be guessing. In such a case, the additional instructions (as above) should be given and the test run restarted.

The intensity of the carrier tone. The mean auditory threshold in the present study was $34 \mathrm{~dB}$. The SISI has been found to be a poor predictor of cochlear pathology in mild hearing $\operatorname{loss}^{9}, 23,32$ and Owens ${ }^{23}$ therefore suggested that the presentation of the carrier tone at 25 or $30 \mathrm{~dB}$ SL may improve the reliability of the test.

Thompson, ${ }^{29}$ however, showed that SISI scores improved with increasing sound intensity in normal ears. Additional false positives in normal groups could thus occur if the intensity of the carrier tone was increased. Thompson also showed that the scores remained low in patients with retrocochlear pathology. He thus suggested that a modified SISI carried out at high SL's would differentially diagnose retrocochlear pathology by the inability to detect these small changes in intensity. High SISI scores have, however, been found in patients with retrocochlear lesions, $9,13,31$ and this modification cannot yet be assumed valid. Further research as to the effect of increased sound intensity on the different clinical pathologies, as well as on normal ears, is indicated.

The number of test increments. The SISI has been found to be susceptible to factors such as fatigue, inattention, and inability to concentrate. ${ }^{7,19}$ Many Ss in the present study reported the operation of such factors. Loeb ${ }^{19}$ found performance on the SISI generally to decline with time. A number of investigators have suggested presenting only ten increments rather than twenty, where all responses to the first ten are either positive or negative. ${ }^{23,} 31$ The split-half reliability of the test has been found to be good at all frequencies except $250 \mathrm{~Hz}^{8}$, and this modification would have the further clinical advantage of considerably reducing the testing time.

$\Lambda$ test of a different type of cochlear pathology. As discussed earlier, the SISI is not a test of recruitment ${ }^{13}$ and is not related to subjective loudness. ${ }^{5}$ It is possible that the ability measured by the SISI is one less frequently associated with cochlear pathology than is recruitment. If this is so, good recruitment tests are obviously more likely to reveal cochlear pathology than are tests of the ability to detect abnormally small sound intensity increments.

The phenomenon measured by the SISI, however, may be characteristic of a 
different type of cochlear pathology from that characteristically revealed by recruitment. ${ }^{14}$ It is possible that this type also occurs subclinically, which would account for the high scores in individuals with normal hearing. If this is so, the SISI would yield additional information concerning the nature of the cochlear pathology, and as such be a very valuable clinical and research tool.

\section{CONCLUSION}

The results of the present study cast doubt on the ability of the SISI, in its present form, to diagnose cochlear pathology differentially and, as such, its value as a site-of-lesion test. It is possible that a modified version of the test may still prove to be reliable and valid. Furthermore, the test may have hitherto undiscovered value, such as in the determination of retrocochlear pathology or in the differentiation of type of cochlear pathology. Further research would therefore seem necessary before this test is discarded as a site-of-lesion test.

It is strongly recommended that the test, even with modification, be used only as part of a battery of site-of-lesion tests, and it is worthwhile to recall the words of Jerger: ${ }^{14}$ The key to successful use of hearing tests in otologic diagnosis seems to be in the employment of multiple test batteries rather than single tests alone.

\section{REFERENCES}

1. Beedle, R.K. and Harford, E.R. (1973): A comparison of acoustic reflex and loudness growth in normal and pathological ears. $J$. Speech Hear. Res., 16, 271-281.

2. Bell, A. (1966): Noise. An occupational hazard and public muisance. Public Health Paper, No. 30, World Health Organization, Geneva, Ch. 8.

3. Brooks, D.N. (1969): The use of the electro-acoustic impedance bridge in the assessment of middle ear function. Int. Audiol., 8, 563-569.

4. Chiveralls, K., and Fitzsimons, R. (1973): Stapedial reflex action in normal subjects. Brit. J. Audiol., 7, 105-110.

5. Colletti, V. (1974): Some stapedius reflex parameters in normal and pathological conditions. J. Laryngol. Otol, 88, 127-137.

6. Feldman, A.S. (1971): Impedance measurement and the middle ear. Maico Audiological Library Series, 9, Report 8.

7. Fowler, E.P. (1950): The recruitment of loudness phenomenon. laryngoscope, 60, 680-685.

8. Griffing, T.S. and Tuck, G.A. (1963): Split-half reliability of the SISI. J. Aud. Res., 3, 159-164.

9. Harford, E.R. (1967): The SISI test. Maico Audio. Lib. Series, 4, Report 9.

10. Hirsh, I.J. (1952): The Measurement of Hearing. McGraw-Hill Book Company, Inc., U.S.A. Chs. 7 and 8.

11. Hirsh, I.J., Pavla, T., and Goodman, A. (1954): Difference limen and recruitment. Arch. Oto-Laryngol, 60, 525-540. 
12. Jepsen, J., (1953): DL difference test. Arch. Oto-Laryngol., 57, 490500 .

13. Jerger, J.F. (1960-61): Recruitment and allied phenomena in differential diagnosis. J. Aud. Res., 1, 145-151.

14. (1962): Hearing tests in Otologic diagnosis. Asha, 4, 139-145.

15. - (1970): Clinical experience with impedance audiometry. Reprint, from the Dept. of Oto-Laryngol., Baylor College of Medicine and the Audio-Vestibular Laboratory, Methodist Hospital, Texas Medical Centre, Houston, Texas. 1-25.

16. Jerger, J., Jerger, S., and Maudlin, L. (1972): Studies in Impedance audiometry. Arch. Oto-Laryngol., 96, 513-523.

17. Jerger, J., Shedd, J.L., and Harford, E. (1959): On the detection of extremely small changes in sound intensity. Arch. Oto-Laryngol., 69, 200-211.

18. Lidén, G. (1970): The stapedius muscle reflex used as an objective recruitment test: A clinical and experimental study. Sensori-neural Hearing Loss, Westholme, G.E.W: and Knight, J., Eds., A Ciba Foundation Symposium, Longman Group Ltd.

19. Loeb, M. (1963): Some factors influencing the effective auditory intensive difference limen. J. Accoust. Soc. Amer., 35, 884-891.

20. Madsen Model ZO-70 Electro-Acoustic Impedance Bridge. Application and Instruction for Use.

21. Metz, O. (1952): Threshold of reflex contractions of muscles of middle ear and recruitment of loudness. Arch. Oto-Laryngol, 55, 536-543.

22. Newby, H.A. (1972): Audiology. Merideth Corporation, U.S.A., 3rd Ed.

23. Owens, E. (1965): The SISI test and VIII th Nerve versus cochlear involvement. J. Speech Hear. Dis. 30, 263-268.

24. Peterson, J.L., and Lidén, G. (1972): Some static characteristics of the

25. Reger, S.N. (1936): Differences in loudness response of the normal and slightly hard-of-hearing ear at intensity levels slightly above threshold. Ann. Otol. Rhinol. Laryngol., 45, 1029-1036.

26. Rubenstein, M., Lipman, B., Yundef, H. and Luz, H. (1970): SISI findings in normal subjects. Acta Oto-Laryngol., 69, 112-116.

27. Silberberg, G. (1972): Recruitment of loudness in the normal young adult. Unpublished research report, Department of Speech Pathology and Audiology, University of the Witwatersrand, Johannesburg.

28. Terkildsen, K. (1962): Intra-aural muscle reflex testing. Int. Audiol, 1 , 228-230.

29. Thompson, G. (1964): A modified SISI technique for selectedicases with suspected acoustic neurinoma. J. Speech Hear. Dis., 29; 231-246.

30. Thomsen, K.A. (1955): Employment of impedance measurements in otologic and otoneurologic diagnostics. Acta Oto-Laryngol, 45, 159-167.

31. Yantis, P.A., and Decker, R.L. (1964): On the short increment sensitivity index (SISI Test). J. Speech Hear. Dis., 29, 231-246.

32. Young, I.M. and Harbert, F. (1967): Significance of the SISI test. $J$. Audit. Res., 7, 303-311. 


\section{BRÜEL \& KJAER}

Manufacturers of

Electro-Acoustical

Instrumentation

\section{FOR AUDIOLOGISTS}

$\star$ Audiometer calibration

$\star$ Hearing aid test sets

* Sound level meters

$\star$ Noise dose meters

$\star$ Artificial ears

* Artificial voice

* Artificial mastoid

$\star$ Frequency analysers

For more information write or phone:

Sole S.A. Agents:--

Telkor Electronics (Pty.) Ltd.

P.O. Box 50856

Randburg 2125

Telephone Jhbg. : 48-9740/8

ALSO:-

Dowson \& Dobson Ltd. +

Durban - Cape Town - Port Elizabeth

Member of the African Oxygen Limited Group. 